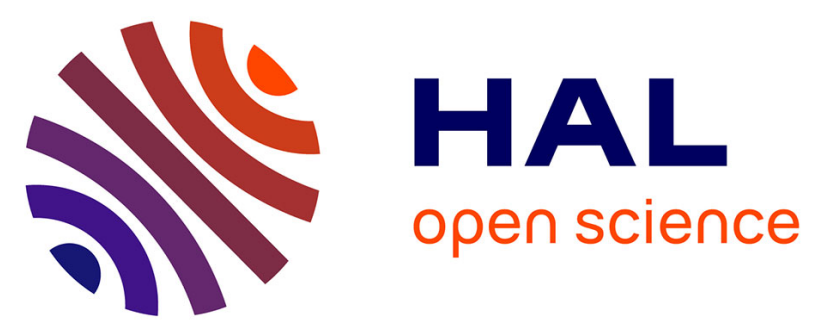

\title{
Structural investigation of fluorophosphate glasses by 19F, 31P MAS-NMR and IR spectroscopy
} Torkia Djouama, Marcel Poulain, Bruno Bureau, Ronan Lebullenger

\section{To cite this version:}

Torkia Djouama, Marcel Poulain, Bruno Bureau, Ronan Lebullenger. Structural investigation of fluorophosphate glasses by 19F, 31P MAS-NMR and IR spectroscopy. Journal of Non-Crystalline Solids, 2015, 414, pp.16-20. 10.1016/j.jnoncrysol.2015.01.017 . hal-01112043

\section{HAL Id: hal-01112043 \\ https://hal.science/hal-01112043}

Submitted on 22 May 2015

HAL is a multi-disciplinary open access archive for the deposit and dissemination of scientific research documents, whether they are published or not. The documents may come from teaching and research institutions in France or abroad, or from public or private research centers.
L'archive ouverte pluridisciplinaire HAL, est destinée au dépôt et à la diffusion de documents scientifiques de niveau recherche, publiés ou non, émanant des établissements d'enseignement et de recherche français ou étrangers, des laboratoires publics ou privés. 


\title{
STRUCTURAL INVESTIGATION OF FLUOROPHOSPHATE GLASSES BY ${ }^{19} \mathrm{~F},{ }^{31} \mathrm{P}$ MAS-NMR AND IR SPECTROSCOPY
}

\author{
T. Djouama ${ }^{1}$, M. Poulain ${ }^{2}$, B. Bureau ${ }^{2}$, R. Lebullenger ${ }^{2}$ \\ ${ }^{1}$ Laboratoire d'Electronique Quantique, USTHB Bab- Ezzouar,16111, Alger, Algérie \\ ${ }^{2}$ Sciences Chimiques, Université de Rennes1, Campus de Beaulieu, 35042 Rennes, France \\ torkia_djouama@yahoo.fr
}

\begin{abstract}
A series of glass samples of composition $\left[(\mathrm{x}) \mathrm{MnF}_{2}-(\mathrm{x}-80) \mathrm{NaPO}_{3}-(20) \mathrm{ZnF}_{2}\right]$ where $\mathrm{x}=0,10,20,30$ and 40, has been prepared. IR and NMR spectroscopy have been performed, especially ${ }^{19} \mathrm{~F}$ MAS and ${ }^{31} \mathrm{P}$ MAS NMR. On the basis of these measurements, glass structure may be described as a hybrid network of $\mathrm{ZnF}_{6}$ and $\mathrm{MnF}_{6}$ octahedra sharing corners and edges and also connectedto tetrahedral fluorophosphate groups $(\mathrm{PX})_{4}$ where $\mathrm{X}=\mathrm{O}^{-}$or $\mathrm{F}^{-}$. Sodium cations fill vacancies of this network.
\end{abstract}

Keywords: Fluorophosphate, glass, vibrational spectroscopy, NMR.

\section{Introduction}

Fluorophosphate glasses have been extensively studied since more than 50 years. One must quote the pioneering work of K. H. Sun in the late forties [1,2]. Since then they have been the subject of numerous papers, especially from German and Russian researchers [3-9]. In addition to rather low temperature processing, they offer low non linear refractive index [6,7] and high UV transmission [9]. Many reported glasses contain aluminium, calcium, strontium or barium polyphosphate as vitrifying compounds Phosphate glasses based on sodium polyphosphate $\mathrm{NaPO}_{3}$ are often hygroscopic, which limits practical use. However the incorporation of fluorides increases chemical durability as this was observed in the $\mathrm{NaPO}_{3}-\mathrm{BaF}_{2}-\mathrm{MF}_{\mathrm{n}}$ ternary systems $(\mathrm{M}=\mathrm{Mg}, \mathrm{Mn}, \mathrm{Zn}, \mathrm{Fe}, \mathrm{Cr}, \mathrm{Ga})$ [10]. In a general way, sodium fluorophosphate glasses are easy to prepare, stable versus devitrification and withstand humid atmosphere [11]. Glass formation has been reported in other multicomponent fluorophosphate glasses [6]. More recently, glasses in the system $\mathrm{NaPO}_{3}-\mathrm{ZnF}_{2}-\mathrm{MnF}_{2}$ have been described [12]. Fluorophosphate glasses usually exhibit low refractive index, small optical non linearity [5-7] and good UV transmission [9].

Structural studies have been implemented by vibrational spectroscopy and solid NMR spectroscopy. Infrared (IR) spectroscopy is currently used to investigate glass structure [13-15]. Indeed, the position of the absorption bands depends on local symmetry as vibration modes are different in tetrahedra and octahedra. In addition, strength constants are also different for bridging and non bridging anions.

The ${ }^{31} \mathrm{P}$ NMR provides accurate information about the way $\mathrm{PO}_{4}$ tetrahedra are connected and the number of non-bridging oxygens. Polyphosphate glasses with the generic formula $\mathrm{M}\left(\mathrm{PO}_{3}\right)_{\mathrm{n}}$ contain long chains made from corner-sharing $\mathrm{PO}_{4}$ tetrahedra. These tetrahedra are referred to as $\mathrm{Q}^{2}$, meaning that they contain two non-bridging oxygens. Incorporation of additional metallic oxides leads to the shortening of these chains and the formation of $\mathrm{Q}^{1}$ tetrahedra. Structure is described as an assembly of phosphate chains in which cations are randomly inserted. The role of fluorine in fluorophosphate glasses is less clearly defined, as it may form isolated $\mathrm{F}^{-}$anions surrounding cations or $\mathrm{PO}_{3} \mathrm{~F}$ tetrahedra. In this case fluorine is expected to be non-bridging.

While very numerous fluoride glasses have been investigated so far [10-16], heavy metal oxyfluoride glasses are less common, insofar as fluoride association with classical oxide glass 
formers-oxides of $\mathrm{B}, \mathrm{Si}, \mathrm{P}, \mathrm{Ge}$-leads to severe losses of volatile compounds. Recent studies on fluoride glasses [17] containing $\mathrm{MnF}_{2}$ confirm that manganese acts as a glass progenitor. The structural studies on fluoride glasses show a vitreous network constructed from large polyhedra (e.g. octahedra or square antiprisms) sharing corners and edges [16].

In this study, a series of glass samples has been prepared according to the general composition rule $(\mathrm{x}) \mathrm{MnF}_{2}-(\mathrm{x}-80) \mathrm{NaPO}_{3}-(20) \mathrm{ZnF}_{2}(0<x<40)$. This corresponds to the substitution of sodium polyphosphate by manganese difluoride. While main physical characteristics of these glasses have been measured and reported [5], structural aspects require special attention. In order to collect information, the structural investigation of these new glasses has been performed using ${ }^{19} \mathrm{~F},{ }^{31} \mathrm{P}$ MAS-NMR and FTIR vibrational spectroscopy. These results should help to understand the way the respective vitreous networks of phosphates and fluorides are combined.

\section{Experimental}

\subsection{Starting materials}

Anhydrous $\mathrm{ZnF}_{2}$ fluoride is a commercial products from Aldrich, with $99.9 \%$ purity. Other starting materials are ammonium hydrogenofluoride $\mathrm{NH}_{4} \mathrm{~F}, \mathrm{HF}$ from WWR (Prolabo) and sodium polyphosphate $\mathrm{NaPO}_{3}$ (97\% Rectapur from WWR Prolabo). $\mathrm{MnF}_{2}$ was prepared by the ammonium fluoride processing, and controlled by X-Ray diffraction.

\subsection{Glass synthesis}

Glasses are prepared at air by melting, fining and casting $[16,18]$. The calculated amount of the starting materials is introduced in a long platinum crucible. After melting is complete, a clear liquid is obtained at a temperature ranging from $700^{\circ} \mathrm{C}$ to $900^{\circ} \mathrm{C}$, depending on $\mathrm{MnF}_{2}$ content. Then this liquid is briefly heated for 5 to $10 \mathrm{mn}$ at higher temperature for the fining step, and cooled into the crucible below $600{ }^{\circ} \mathrm{C}$ to increase viscosity and to minimize sub-liquidus nucleation. Finally it is cast between two brass walls that are heated at temperature close to $\mathrm{Tg}$, that is roughly $250^{\circ} \mathrm{C}$. A final annealing stage is carried out for 6 hours at a temperature $10 \mathrm{~K}$ lower than $\mathrm{Tg}$ to remove residual thermal stresses prior to polishing.

The absence of a crystalline phase in the samples synthesized was checked on a DRON-2.0 X-Ray diffractometer using the filtered $\mathrm{Cu} K \alpha$ radiation.

\subsection{Characterizations}

The glass system under investigation is defined by the following composition rule:

$(\mathrm{x}) \mathrm{MnF}_{2}-(\mathrm{x}-80) \mathrm{NaPO}_{3}-(20) \mathrm{ZnF}_{2}(10<x<40)$ while the manganese-free $20 \mathrm{ZnF}_{2}-80 \mathrm{NaPO}_{3}$ glass was also studied for comparison.

The absorption spectra of the samples, either bulk or powders, were recorded on a Fourier transform infrared (FTIR) spectrophotometer Merlin Digilab FTS 3000 operating between 4000 and $400 \mathrm{~cm}^{-1}$ from powdered glasses dispersed in dehydrated $\mathrm{KBr}$ pellets. Powdered samples and $\mathrm{KBr}$ were kept at $110^{\circ} \mathrm{C}$ before the analysis to remove adsorbed water.

FTIR spectroscopy method is used to confirm the identification of groups formed by glass formers, modifiers and anions and the type of chains. FTIR is also useful to detect the presence of hydroxyl radicals.

The ${ }^{31} \mathrm{P}$ and ${ }^{19} \mathrm{~F}(\mathrm{I}=1 / 2)$ NMR spectra were recorded at room temperature on an Avance 300 Bruker spectrometer operating at respectively 121 and $282 \mathrm{MHz}$ with a $2.5 \mathrm{~mm}$ MAS probe. The spectra were recorded at a maximum spinning speed of $30 \mathrm{kHz}$ in order to simultaneously average the chemical shift and reduce the dipolar interaction. Then, the remaining broadness of the lines is due to the isotropic chemical shift distributions characteristic of the vitreous states. Due to this strong residual line broadness, a rotor-synchronized spin echo sequence was applied to refocus the whole magnetization and thus to avoid any distortion of the baseline. The Fourier Transformation were implemented from the whole echoes (so-called full shifted echoes) in order to increase the signal to noise ratio and to directly obtain absorption mode lineshapes [19-20]. The ${ }^{31} \mathrm{P}$ spectra were recorded 
with a first pulse of $1 \mu \mathrm{s}(\pi / 2)$ and $2 \mu \mathrm{s}(\pi)$ for the second pulse. The recycle time was 30 s, which was sufficient for full relaxation.The ${ }^{19} \mathrm{~F}-{ }^{31} \mathrm{P}$ CP MAS NMR spectra were recorded with a contact time of $1 \mathrm{~ms}$ and a recycle delay of $2 \mathrm{~s}$ ensuring the quantitativity of the spectra.

The external reference used for the chemical shifts is $\mathrm{C}_{6} \mathrm{~F}_{6}$ for ${ }^{19} \mathrm{~F}$ spectra and $\mathrm{NaPO}_{3}$ for ${ }^{31} \mathrm{P}$ spectra. The simulations of the experimental spectra were performed thanks to the dmfit software [21].

\section{Results}

\subsection{Infrared spectra}

\section{- Bulk samples}

The transmission spectrum of the $30 \mathrm{MnF}_{2}-50 \mathrm{NaPO}_{3}-20 \mathrm{ZnF}_{2}$ glass has been recorded between 1000 and $5000 \mathrm{~cm}^{-1}$. The thinner sample (dashed line) evidences the complex structure of the absorption bands (see Fig. 1).

The main features that emerge from this figure are:

- The absorption band around $3200 \mathrm{~cm}^{-1}$ that originates from hydroxyl groups.

- An intense band at $2200 \mathrm{~cm}^{-1}$ that defines the transmission limit of the sample.

- Another band around $1600 \mathrm{~cm}^{-1}$.

Optical transmission is restricted to the visible spectrum because the electronic transitions of $\mathrm{Mn}^{2+}$ cations in octahedral ligand field lead to strong UV absorption [22,23]. It is limited to $4.5 \mu \mathrm{m}$ in the mid-infrared by the first overtone of the $\mathrm{P}-\mathrm{O}$ vibrations as this has been shown in fluoride glasses doped with phosphates [24].

\section{- Powdered samples}

Infrared transmission of powdered samples of the same glass in $\mathrm{KBr}$ pellets is shown in Fig. 2. The spectrum is limited to $400 \mathrm{~cm}^{-1}$, as $\mathrm{KBr}$ is no more transparent beyond this frequency. The comparison with bulk glass shows that the absorption observed between 1500 and $2500 \mathrm{~cm}^{-1}$ corresponds to the first overtones of the fundamental absorption bands of the $\mathrm{PO}_{4}$ tetrahedra [24].

The vibrational behavior of phosphate salts has been widely studied [25-27]. The infrared absorption spectrum of phosphates brings out almost endless chains of polyphosphate. It encompasses bands associated with stretching vibrations of $\left[\mathrm{PO}_{2}\right]^{-}$and $[\mathrm{POP}]$ groups that correspond to connections, terminal $\left(\mathrm{PO}^{-}\right)$and bridging $\mathrm{Q}^{2}$. The allocation of band network phosphate is based on the work of Efimov [26]. In particular, this concerns the different modes of vibration of the long chains and the short chains in the case of pyrophosphate glasses. The IR absorbance spectra of the studied glasses are shown in figure 2, which shows bands at: 530, 770, 870, 1000, 1095, 1165 and $1275 \mathrm{~cm}^{-1}$. The assignment of these bands is shown in Table 1 . Some bands also exist in the pure $\mathrm{NaPO}_{3}$ glass but they have a very low intensity. This concerns the bands located at 530, 770 and $870 \mathrm{~cm}^{-1}$, respectively attributed to the deformation mode of $\mathrm{PO}$ bonds of the $\mathrm{Q}^{2}$ tetrahedra, the symmetric stretching mode of POP bonds dimers $\mathrm{Q}^{2}$, and the antisymmetric mode of POP connections between tetrahedra $\mathrm{Q}^{2}$. However, the intensity of these bands increases gradually as the fluoride addition increases up to 25 mol\% and subsequently decreases. On the other hand, the band observed at $999 \mathrm{~cm}^{-1}$ in pure $\mathrm{NaPO}_{3}$ glass, has undergone a slight shift to $1018 \mathrm{~cm}^{-1}$ with the introduction of $\mathrm{MnF}_{2}$, the latter being attributed to the symmetric stretching mode of terminal P-O bonds of $\mathrm{Q}^{1}$.

An additional weak band appears around $435 \mathrm{~cm}^{-1}$ and becomes more visible when $\mathrm{MnF}_{2}$ increases; it is attributed to the vibration mode of $\mathrm{Mn}-\mathrm{F}$ octahedra $\mathrm{MnF}_{6}$. The presence of octahedral $\left[\mathrm{MnF}_{6}\right]$ has actually been observed in fluoride glasses and oxyfluorides, using IR spectroscopy [28,29].

Finally the band located at $1277 \mathrm{~cm}^{-1}$ is characteristic of phosphate groups. It is attributed to the antisymmetric stretching mode of $\mathrm{PO}$ terminal bonds, tetrahedra $\mathrm{Q}^{2}$ fades and disappears completely beyond $15 \% \mathrm{MnF}_{2}$. This band is observed in the spectra of tungsten fluorophosphates glasses [24]

Table 1 summarizes the functions of the vibration modes observed in the spectra of our vitreous samples. 


\section{2 ${ }^{31}$ P MAS-NMR spectra}

Fig.3 shows respectively the ${ }^{31} \mathrm{P}$ MAS-NMR spectra obtained first from crystalline sodium metaphosphate $\mathrm{NaPO}_{3}$ used as a structural model, and glasses in the system $(\mathrm{x}) \mathrm{MnF}_{2}-(\mathrm{x}-80) \mathrm{NaPO}_{3}-$ $(20) \mathrm{ZnF}_{2}$ with $\mathrm{x}=0,10,20,30,40$ and $50 \%$ molar. The analysis of the last two samples $(\mathrm{x}=40$ and $50 \% \mathrm{MnF}_{2}$ ) could not be performed because of an excess of manganese fluoride. Manganese ion $\mathrm{Mn}^{2+}$ is a paramagnetic element $\left(3 d^{5}\right)$ with an electronic magnetic moment, which interacts with the nuclear moment of ${ }^{31} \mathrm{P}$ and causes a strong broadening of NMR lines.

The vitreous $\mathrm{NaPO}_{3}$ spectrum presents a band centred at $-20 \mathrm{ppm}$. This line position is characteristic of the $\mathrm{Q}^{2}$ tetrahedral units [30-32]. This observation agrees with previous studies on sodium metaphosphate $\mathrm{NaPO}_{3}$. Its structure consists in the arrangement of $\mathrm{PO}_{4}$ tetrahedra, corner linked and forming a mono dimensional chain $\left[\left(\mathrm{O}_{2} \mathrm{PO}_{2 / 2}\right)\right]$. The $\mathrm{Na}^{+}$cations, as network modifier, are located between the chains.

The spectrum of pure zinc and sodium fluorophosphate glass of the composition $20 \mathrm{ZnF}_{2}-80 \mathrm{NaPO}_{3}$ (see Fig. 3) shows a second line of lower intensity than the first one. It is observed at around $-3 \mathrm{ppm}$. This line is attributed to the $\mathrm{Q}^{1}$ tetrahedra according to the authors previously cited. This result is quite expected, since $\mathrm{Q}^{1}$ correspond to groups based on bits of string [30,33]. Indeed, it confirms that the fluorine takes place into $\mathrm{PO}_{3} \mathrm{~F}$ tetrahedra, breaks the chains as monovalent element, and so decreases the reticulation of the tetrahedral network. This observation is corroborated by the ${ }^{19} \mathrm{~F}-{ }^{31} \mathrm{P} \mathrm{CP}-\mathrm{MAS}$ spectrum shown in Fig. 5. Indeed, the relative intensities of the both lines are inverted by comparison to the ${ }^{31} \mathrm{P}$ direct acquisition, at the expense of the $\mathrm{Q}^{2}$ tetrahedra. This is clearly due to the presence of fluorine in the close neighborhood of the $\mathrm{Q}^{1}$ tetrahedron phosphorus, which is not the case for the $\mathrm{Q}^{2}$. Then, the introduction of $\mathrm{MnF}_{2}$ leads to the increase and the broadening of the line assigned to $\mathrm{Q}^{1}$. This line extends now from -3 to $0 \mathrm{ppm}$. These tetrahedra $\mathrm{Q}^{1}$ emerged continuously with the incorporation of $\mathrm{MnF}_{2}$, suggesting that the fluorine atoms, added as $\mathrm{MnF}_{2}$, gradually cut chains of phosphate tetrahedral as described above.

All the ${ }^{31} \mathrm{P}$ spectra have been reconstructed in order to measure precisely the relative weight of the $\mathrm{Q}^{1}$ and $\mathrm{Q}^{2}$ species. The results are reported in table 2 and their variations are given in Fig. 4. It confirms the progressive vanishing of $\mathrm{Q}^{2}$ with the increase of the fluorine content in the composition.

\section{3 ${ }^{19}$ F MAS-NMR spectra}

The ${ }^{19} \mathrm{~F}$ MAS-NMR spectra of the studied glasses are shown in Fig. 6 . The fluorine broad line is observed at $95 \mathrm{ppm}$ for the $20 \mathrm{ZnF}_{2}-80 \mathrm{NaPO}_{3}$ initial glass, in agreement with previous studies [34]. This line is attributed to the fluorine ions directly bonded to phosphorus as met in $\mathrm{PO}_{3} \mathrm{~F}$ entities for example. This line is strongly broadened as manganese content increases. It results from the paramagnetism of $\mathrm{Mn}^{2+}$ cations. Other weak signals appear in the background line, especially around 60-70 ppm. This range of chemical shift encompasses the line position of ${ }^{19} \mathrm{~F}$ in $\mathrm{MnF}_{2}$. Note that the two large side bands are spinning side bands due to the Magic Angle Spinning of the sample. While they are not significant, they make more difficult the identification of other possible ${ }^{19} \mathrm{~F}$ lines.

\section{Discussion}

In pure $\mathrm{NaPO}_{3}$, either in the crystalline form or in the vitreous state, $\mathrm{PO}_{4}$ tetrahedra form chains or rings. Thus tetrahedra share only two corners, which corresponds to $\mathrm{Q}^{2}$ tetrahedra. As a consequence, IR spectrum shows absorption bands typical of P-O bonds between phosphorous and bridging oxygen and non-bridging oxygen. As reported in table 1, IR spectrum also shows deformation of P-O-P chains, and also the stretching of the M-F bonds ( $\mathrm{Zn}$ and $\mathrm{Mn}$ ).

As the fluoride content increases, bridging oxygens is replaced by two non-bridging fluorides, leading to shorter chains and the transformation of $\mathrm{Q}^{2}$ tetrahedra into $\mathrm{Q}^{1}$ [35]. The changes in IR absorption spectra resulting from fluoride incorporation are consistent with this scheme. A confirmation is provided by NMR measurements. 
The first information given by NMR measurements concerns the relative number of $\mathrm{Q}^{2}$ and $\mathrm{Q}^{1}$ tetrahedra as a function of composition. Insofar as all glass components $-\mathrm{NaPO}_{3}, \mathrm{ZnF}_{2}, \mathrm{MnF}_{2}$ - may act as glass progenitors, there are several possibilities for constructing the vitreous network. The first one consists in the mere insertion of $\mathrm{MF}_{6}$ octahedra into the set of polyphosphate chains. This structural hypothesis corresponds to the coexistence of two types of networks, oxide and fluoride, with ionic interactions. The other possibility leads to the formation of a hybrid network that associates tetrahedra and octahedra. This implies the breaking of the long -O- $\mathrm{PO}_{2}-\mathrm{O}$ - chains by non-bridging fluorine. The NMR results clearly support this hypothesis, which is consistent with previous work [35]. While pure $\mathrm{NaPO}_{3}$ glass contains almost exclusively $\mathrm{Q}^{2}$ tetrahedra, the incorporation of $20 \mathrm{~mol} \% \mathrm{ZnF}_{2}$-that is the starting composition of this study- leads to the formation of $40 \% \mathrm{Q}^{1}$ tetrahedra at the expense of the original $\mathrm{Q}^{2}$ s. The mechanism corresponds to the replacement of one bridging oxygen by two nonbridging fluorides. In the glass containing $30 \mathrm{~mol} \% \mathrm{MnF}_{2}$, only $5 \% \mathrm{Q}^{2}$ tetrahedra are remaining. Thus glass structure contains almost exclusively $\mathrm{P}_{2}(\mathrm{O}, \mathrm{F})_{7}$ dimers. Indeed, these large complex anions make a diffusion barrier for structural ordering, which enhances glass formation. However the vitreous network based on $\mathrm{PX}_{4}$ tetrahedra does not exist anymore. These fluorophosphate glasses are rather similar to heavy metal fluoride glasses, with a vitreous network constructed from large polyhedra octahedra in this case- and $\mathrm{P}_{2} \mathrm{X}_{7}$ groups.

Less accurate information is provided by the ${ }^{19} \mathrm{~F}$ NMR because of the broadness of the lines due to the paramagnetic manganese ion presence. Despite the isostructural character of both fluorides, NMR signal is very different for $\mathrm{ZnF}_{2}(-36 \mathrm{ppm})$ and for $\mathrm{MnF}_{2}(+66 \mathrm{ppm})$. Neither of these chemical shifts is observed in the glass network confirming that fluorines are well incorporated into the phosphate vitreous network. It is especially clear for the initial composition containing only $\mathrm{ZnF}_{2}$ for which only one well resolved line is observed at $95 \mathrm{ppm}$. Besides, assuming a large disordering in glass structure and a 3 coordination number of fluorine versus cations, four different situations could be encountered for the environment of the free fluorine anions that are not linked to phosphorus :

1) 3 Zinc cations

2) $2 \mathrm{Zn}$ and $1 \mathrm{Mn}$

3) $1 \mathrm{Zn}$ and $2 \mathrm{Mn}$

4) $3 \mathrm{Mn}$

NMR signal in the second and the third case should be intermediate between $-36 \mathrm{ppm}$ and $66 \mathrm{ppm}$. In practice a weak signal around $60 \mathrm{ppm}$ appears in the glass containing $20 \mathrm{~mol} \% \mathrm{MnF}_{2}$. This suggests that structural units in glass are close to the local arrangement in crystalline manganese difluoride, that is $\mathrm{MnF}_{6}$ octahedra sharing edges and apexes, as it may be observed in rutile structure. Nevertheless, this type of environment is clearly a minority and is observed only for the manganese-rich compositions. Thus, $20 \%$ for $\mathrm{MnF}_{2}$ can be considered as a limit for a homogeneous dissolution of $\mathrm{Mn}^{2+}$ ions into the structural network.

\section{Conclusion}

The introduction of manganese difluoride $\mathrm{MnF}_{2}$ at the expense of $\mathrm{NaPO}_{3}$ in the $80 \mathrm{NaPO}_{3}-$ $20 \mathrm{ZnF}_{2}$ glass results in structural changes that have been studied by infrared spectroscopy and NMR. While vitreous sodium polyphosphate consists ideally of $\left(\mathrm{PO}_{4}\right)_{\mathrm{n}}$ indefinite chains trapping isolated $\mathrm{Na}^{+}$ cations, the incorporation of $20 \% \mathrm{ZnF}_{2}$ reduces chain length, as $40 \% \mathrm{PX}_{4}$ tetrahedra are terminal. With further incorporation of $\mathrm{MnF}_{2}, \mathrm{Q}^{2}$ tetrahedra disappear almost completely. This means that only pyrophospate groups $\mathrm{P}_{2}(\mathrm{O}, \mathrm{F})_{7}$ remain as phosphorus-based structural units.Vitreous network associates these $\mathrm{P}_{2}(\mathrm{O}, \mathrm{F})_{7}$ groups and $\mathrm{MF}_{6}$ octahedra. There are two types of fluorine anions, those linked to phosphorus, and those linked to $\mathrm{Mn}$ and $\mathrm{Zn}$ in a rutile-like arrangement.

The high concentration of divalent manganese modifies the magnetic and optical properties of the base glass. Complementary physical measurements are under way. 


\section{References}

[1] K. H. Sun, M. L. Huggins, "fluorophosphate glass", US patent 2481700, 13.9.1949, US Patent $2578325,11.12 .1951$

[2] K. H. Sun, "Fluorophosphate Glass", US Patent 2511225 \& 2511227, 13.6.1950, US Patent 2430539, 11.11.1947

[3] G.I. Veksler, K. K. Evstrop'ev, B. S. Kondrat'eva, Inorg. Mater. 10 (1974) 145-148

[4] W. Jahn, Glastech. Ber. 34 (1961) 107-120

[5] Ernst Leitz Gmbh, Fluorophosphate optical glass, German Patent P 2514017.4, 29/03/1975, FrenchPatent 2306174, 17/03/1976

[6] S. Stokowsky, "Laser Glass", in Lawrence Livermore National Laboratory Annual Report 1979, Edited by L. Coleman and J. Strack, Lawrence Livermore Laboratory, Livermore, CA, 1980 (UCRL-50021-79)

[7] R. K. Sandwick, R. J. Scheller, K. H. Mader, "Production of high homogenous fluorophosphate laser glass", Proc. SPIE 171 (1979) 161-164

[8] J. J. Videau, J. Portier, C. Fouassier, Mater. Res. Bull. 14 (1979)177-184

[9] L. Cook, K. H. Mader, J. Am. Ceram. Soc. 65 (1982) 597-60

[10] M. Matecki, M. Poulain, J. Non-Cryst. Solids 56 (1983) 111.

[11] T. Djouama, A. Boutarfaia, M. Poulain, J. Phys. Chem. Solids , 69 (2008) 2756-2763

[12] T. Djouama, M. Poulain, M.T. Soltani and A. Boutarfaia, J.Opt.Adv. Mater. Symposia, 3(2009) 358-361,

[13] J. Wong and C. A. Angell, Glass Structure by Spectroscopy, p. 409. Marcel Dekker, New York, (1976).

[14] B. Karmakar, P. Kundu \& R.N. Dwivedi, J. Non-Cryst. Solids, 289(2001) 155-162

[15] A. Agarwal, K. M. Davis, and M. Tomozawa, J. Non-Cryst. Solids, 185 (1995)191-98

[16] M. Poulain - Glass compositions and structure, in "Fluoride glasses", Alan E. Comyns Ed., J.Wiley \& Sons, 1989, Chichester, Chapter 1, 11-48. Also: Fluoride glasses: properties, technology and applicationsIn "Photonic Glasses and Glass Ceramics", S. Ganapathy Ed., Research Signpost, Kerala (India), ISBN: 978-81-308-0375-3 (2010), 1-28

[17] T. Djouama, A. Boutarfaia, M. Poulain, J. Opt. Adv. Mater. Rapid Commun. 1 (2007) 122.

[18] M. Poulain, G. Maze, Chemtronics, 3 (1988)77-85

[29] P.J. Grandinetti, J.H. Baltisberger, A. Llor, Y.K. Lee, U. Werner, M.A. Eastmann, A. Pines, J. Magn. Reson. A 103 (1993) 72.

[20] B. Bureau, G. Silly, J.Y. Buzaré, J. Emery, C. Legein and C. Jacoboni, J. Phys. Condens. Mater 9 (1997) 6719.

[21] D. Massiot, I. Farnan, N. Gautier, D. Trumeau, A. Trokiner,J.P. Coutures, Solid State Nucl. Magn. Reson. 4 (1995) 241.

[22] L. N. Feuerhelm, S. M. Sibley, and W. A. Sibley, J. Solid State Chem., 54 (1984)164

[23] M. A Bunuel, R.Alcala and R. Cases. J.Phys. Mater. 10, (1998)9343-9358

[24] G. Poirier, M. Poulain, Y. Messaddeq, S. J. L Ribeiro, J. Non-Cryst. Solids 351(2005) 293-298

[25] D.E.C. Corbridge, In Topics in Phosphorus Chemistry, 6, Wiley Interscience, New-York, 235, (1969)

[26] A.M. Efimov, J. Non-Cryst. Solids, 209 (1997) 209-226

[27] A. Rulmont, R.Cahay, M. Liegeois-Duckaerts, P.Tarte, Eur. J. Solid State Inorg. Chem., 28, (1991)207-219

[28] P. P. Fedorov, Kristallografiya, 42 (1997) 1141-1152,

[29] L. N. Ignat'eva, S. A. Polishchuk, T. F. Antokhina, and V. M. Buznik, Glass Phys. Chem. 30 (2004) 139-141.

[30] X. J. Xu, D. E. Day, R. K. Brow, P. M. Callahan, Phys. Chem. Glasses, 36, (1995) 264-271

[31] S. W. Martin, Eur. J. Solid StateInorg. Chem, 28 (1991)163-205

[32] R. K. Sato, R. J. Kirkpatrick, R. K. Brow, J.Non-Cryst.Solids, 143 (1992) 257

[33] P. Hartmann, J. Vogel, B. Schnabel, J. Magn.Res. A, 111(1994) 110,

[34] R.K. Brow, Z. A. Osbone, R. J. Kirkpatrick, J. Mater. Res., 7 (1992) 1892-1899

[35] F. Gan, Y. Jiang, F. Jiang, J. Non. Cryst. Solids, 52 (1982) 263-273. 
Tables \& Figures

Table 1. Assignment of vibration modes in IR for glasses in : $\mathrm{xMnF}_{2}-(80-\mathrm{x}) \mathrm{NaPO}_{3}-20 \mathrm{ZnF} 2$ system $(\mathrm{x}=0,10,20,30,40,45,50 \%$ molar $)$

\begin{tabular}{|c|c|}
\hline Positions of bands $\left(\mathrm{cm}^{-1}\right)$ & Attribution \\
\hline $435-445$ & Stretching mode of M-F bonds (on $\mathrm{MnF}_{6}$ and $\mathrm{ZnF}_{6}$ octahedra) \\
\hline $540-570$ & Deformation modein $\mathrm{Q}^{2}$ tetrahedra( $\delta \mathrm{O}-\mathrm{P}-\mathrm{O}$ and $\left.\delta \mathrm{P}-\mathrm{O}-\mathrm{P}\right)$ \\
\hline $745-817$ & $\begin{array}{lcllll}\text { Symmetric stretching mode connections } & \text { P-O } & \text { bridging groups } \\
\text { intermediate } \mathrm{PO}_{2} \text {-tetrahedra } \mathrm{Q}^{2} .\end{array}$ \\
\hline $920-935$ & $\begin{array}{l}\text { Elongation asymmetric links (P-O-P) between } \mathrm{Q}^{2} \text { tetrahedra. } \\
\left.\text { (frequency rated } v_{\text {as }}\left(\mathrm{PO}_{2}^{-}\right)\right)\end{array}$ \\
\hline 1018-1027 & Elongation symmetric connections $\mathrm{P}-\mathrm{O}$ terminal $\left(\mathrm{Q}^{2}\right)$. \\
\hline $1128-1150$ & Elongation symmetric connections $\mathrm{P}-\mathrm{O}$ terminal $\left(\mathrm{Q}^{1}\right.$ of $\mathrm{PO}_{3}{ }^{2-}$ group $)$ \\
\hline
\end{tabular}

Table 2.Values of chemical shifts of phosphorus and \% for each environment (Reference used: $85 \%$. $\mathrm{H}_{3} \mathrm{PO}_{4}$ )

\begin{tabular}{|c|c|c|c|c|c|}
\hline \multirow{2}{*}{$\begin{array}{c}\text { Compositions } \\
(\% \mathrm{~mol})\end{array}$} & \multicolumn{2}{|l|}{ Chemical shift } & \multicolumn{2}{|c|}{$\%$ of $\mathrm{P}$ in each environment } & \multirow{2}{*}{ F/P Ratio } \\
\cline { 2 - 5 } & $\mathrm{Q}^{1}$ & $\mathrm{Q}^{2}$ & $\mathrm{Q}^{1}$ & $\mathrm{Q}^{2}$ & \\
\hline $\mathrm{NaPO}_{3}$ glass & $\mathrm{N} / \mathrm{A}$ & -21 & 0 & 100 & 0 \\
\hline $\begin{array}{c}80 \mathrm{NaPO}_{3} \\
0 \mathrm{MnF}_{2}\end{array}$ & -3 & -20 & 40 & 60 & 0.5 \\
\hline $\begin{array}{c}70 \mathrm{NaPO}_{3} \\
10 \mathrm{MnF}_{2}\end{array}$ & -0.5 & -19 & 84 & 16 & 0.86 \\
\hline $\begin{array}{c}60 \mathrm{NaPO}_{3} \\
20 \mathrm{MnF}_{2}\end{array}$ & 2 & -19 & 90 & 10 & 1.08 \\
\hline $\begin{array}{c}50 \mathrm{NaPO}_{3} \\
30 \mathrm{MnF}_{2}\end{array}$ & 2 & -19 & 95 & 5 & 2 \\
\hline
\end{tabular}




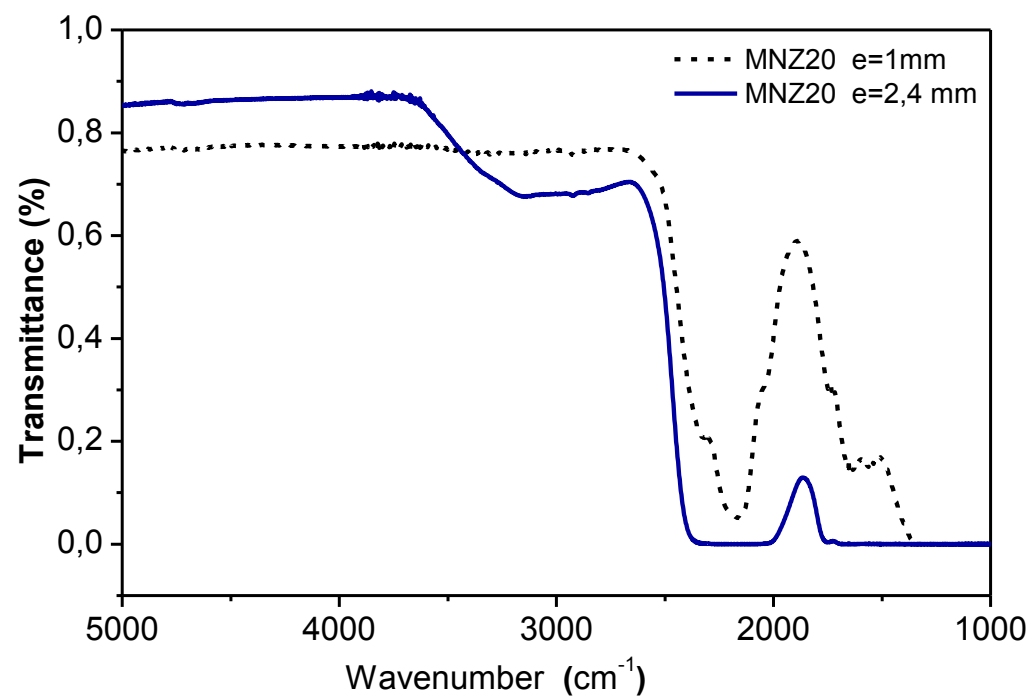

Figure 1. IR transmittance of $30 \mathrm{MnF}_{2} 50 \mathrm{NaPO}_{3}-20 \mathrm{ZnF}_{2}$ glass sample 


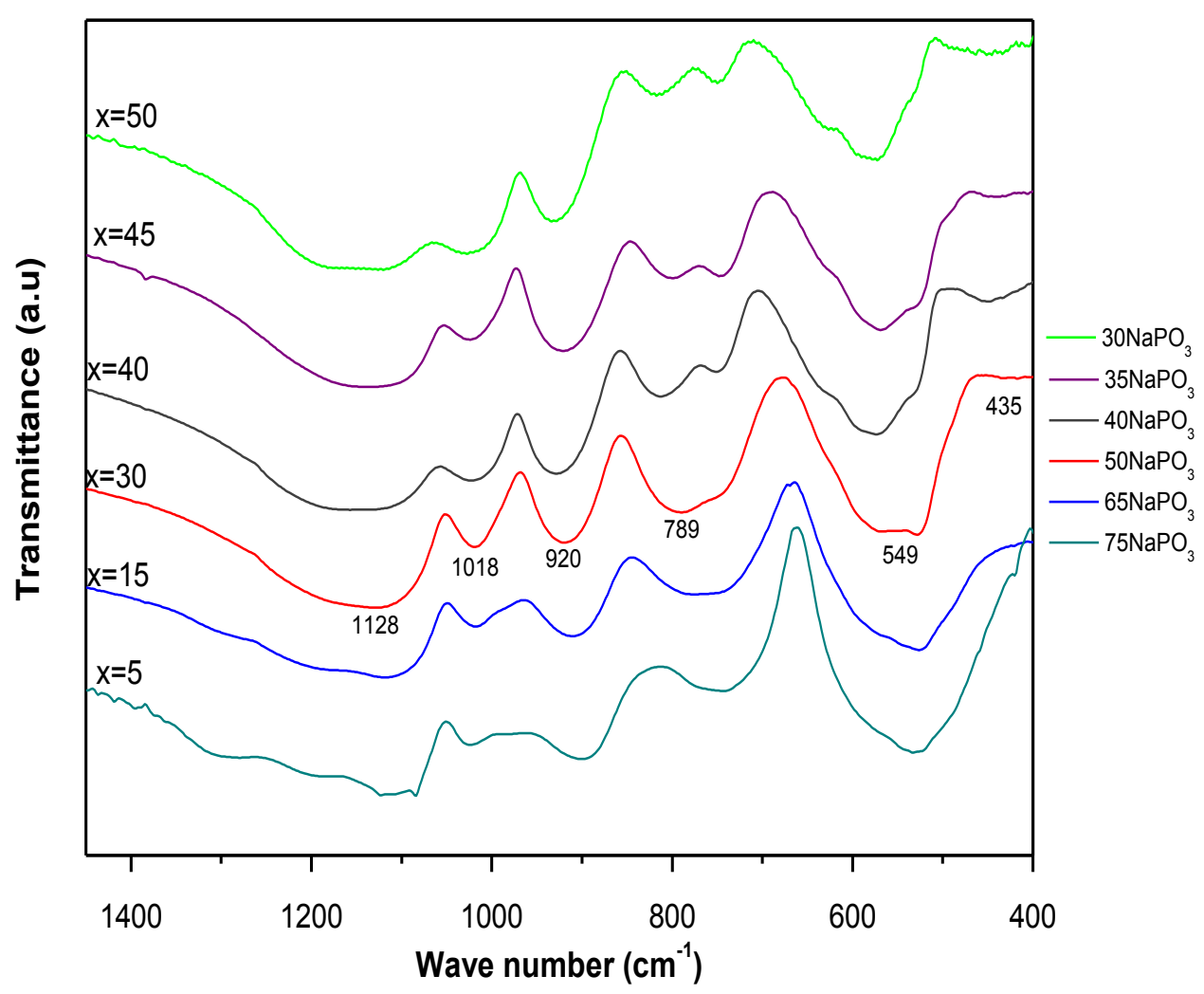

Figure 2. Infrared absorption spectra of glasses in the $\mathrm{xMnF}_{2}-(80-\mathrm{x}) \mathrm{NaPO}_{3}-20 \mathrm{ZnF}_{2}$ system 


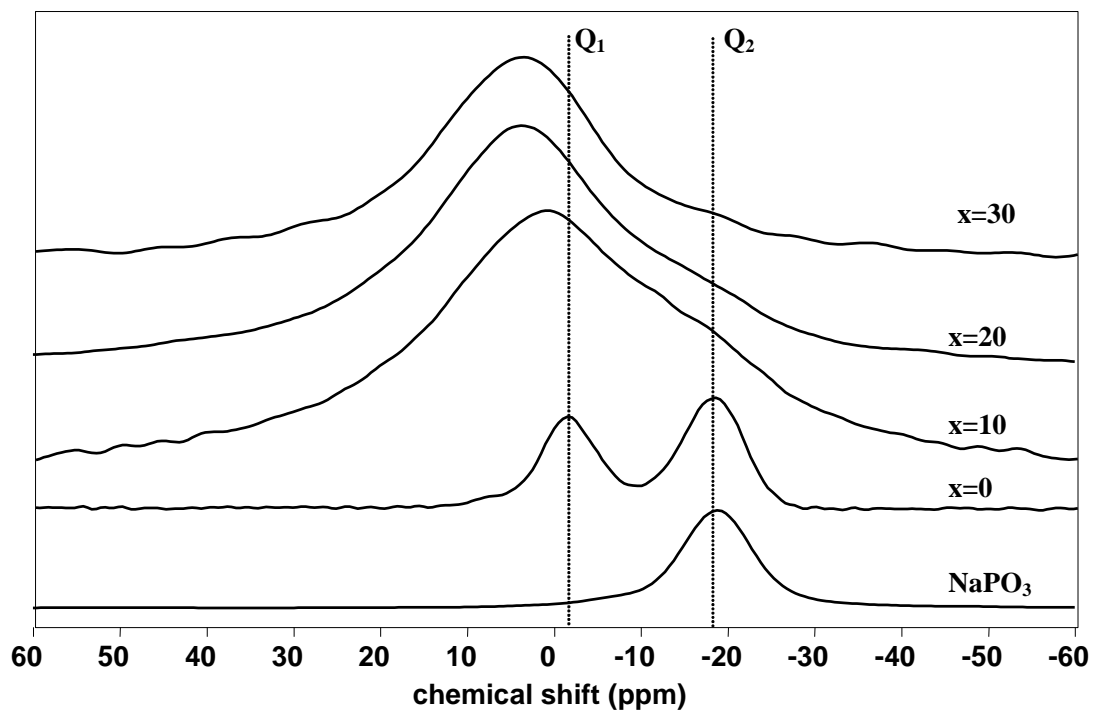

Figure 3. ${ }^{31} \mathrm{P}$ NMR MAS spectra of $(\mathrm{x}) \mathrm{MnF}_{2}-(\mathrm{x}-80) \mathrm{NaPO}_{3}-(20) \mathrm{ZnF}_{2}$ glasses

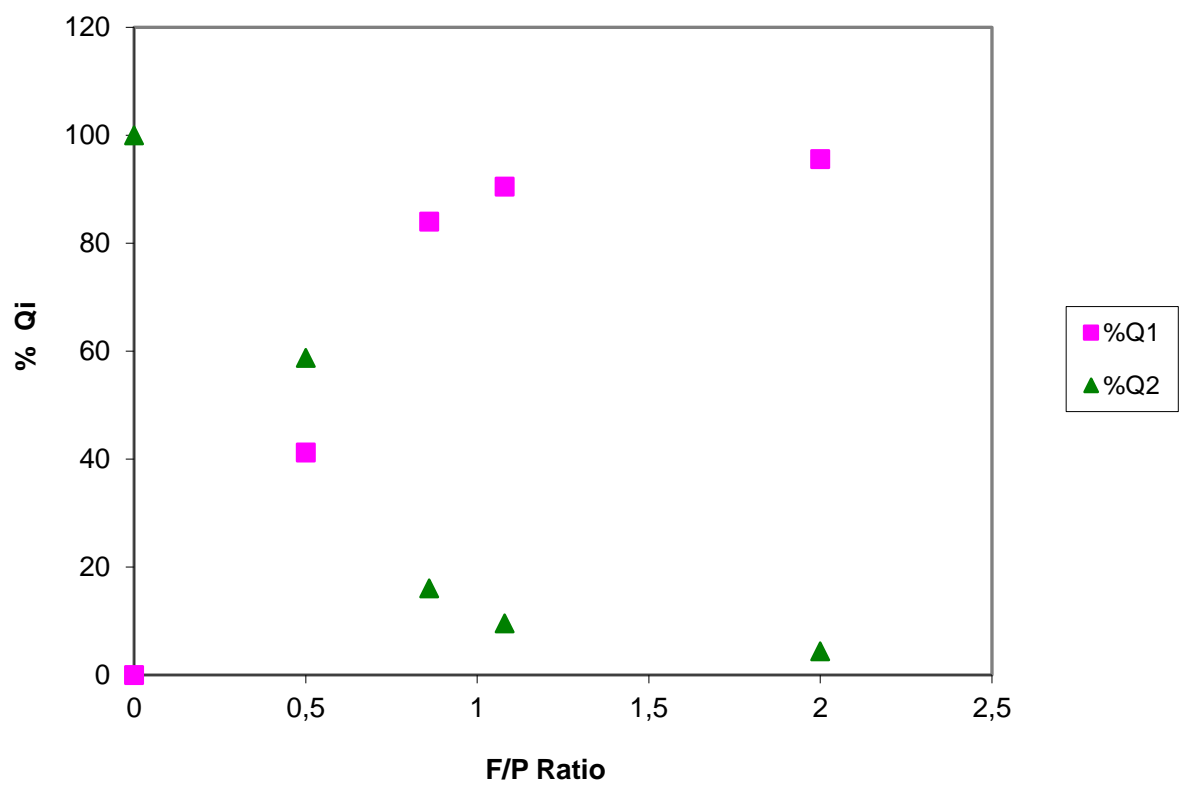

Figure 4. Variation of respective amounts of $\mathrm{Q}^{1} \& \mathrm{Q}^{2}$ with the $\mathrm{F} / \mathrm{P}$ ratio 


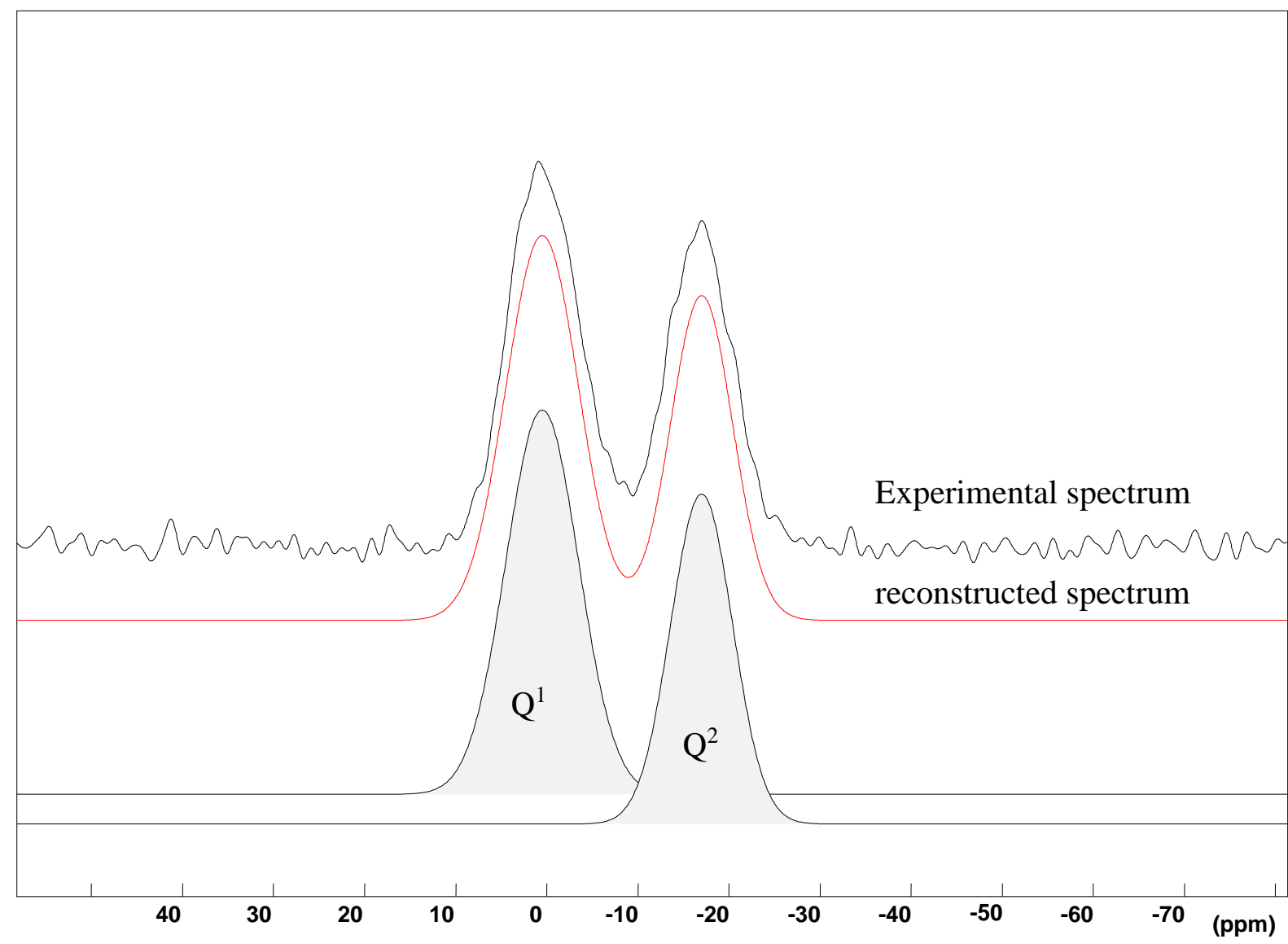

Figure 5. ${ }^{19} \mathrm{~F}_{-}{ }^{31} \mathrm{P}$ CP-MAS spectrum and its reconstruction. The relative intensities of the $\mathrm{Q}^{1}$ and $\mathrm{Q}^{2}$ tetrahedra are inverted compared to the spectrum of the figure $3(\mathrm{x}=0)$. 


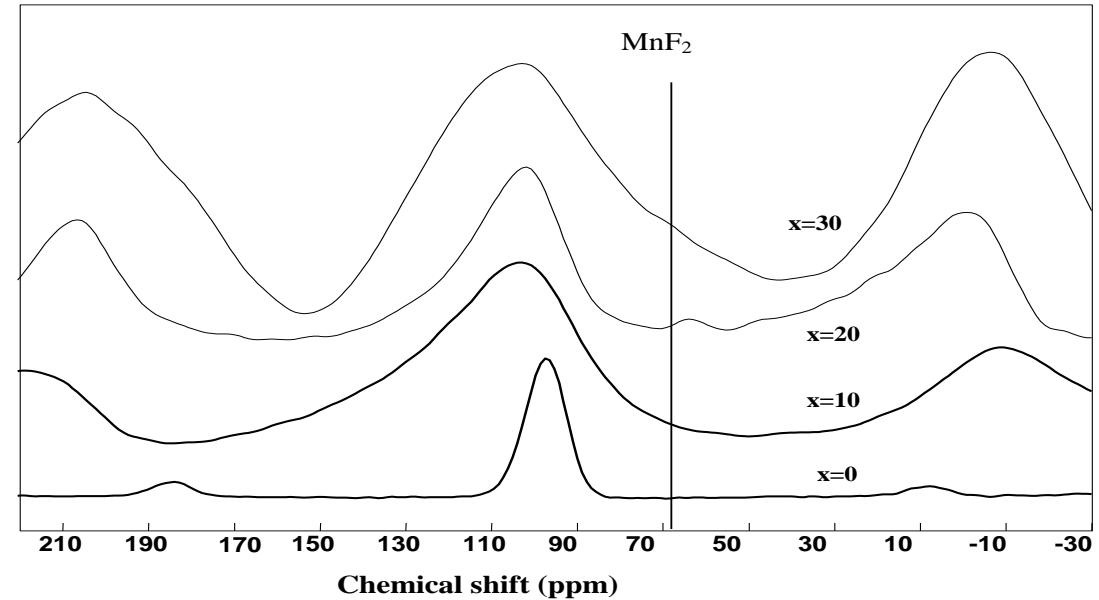

$\mathrm{MnF}_{2}: \delta=66 \mathrm{ppm}$

$\mathrm{ZnF}_{2}: \delta=-36 \mathrm{ppm}$

Figure 6. ${ }^{19} \mathrm{~F}$ NMR MAS spectra of $\mathrm{xMnF}_{2}-(\mathrm{x}) \mathrm{MnF}_{2}-(\mathrm{x}-80) \mathrm{NaPO}_{3}-(20) \mathrm{ZnF}_{2}$ glasses 